\title{
Synthesis of a Fluorophore with Improved Optical Brightness
}

\author{
Macduff Okuom ${ }^{1}$, Mark Wilson ${ }^{1}$, Jordan Groathouse ${ }^{1}$, Junsik Lee ${ }^{2}$, \\ Dave Symonsbergen ${ }^{2}$, Casey Gustafson ${ }^{1}$, Mitch Trauernicht ${ }^{1}$, Homar Barcena ${ }^{1}$, \\ Cassie Reicks ${ }^{1}$, Sharmin Sikich ${ }^{1}$, Raychelle Burks ${ }^{1}$, Andrea Holmes ${ }^{1}$ \\ ${ }^{1}$ Chemistry Department, Doane College, Crete, USA \\ ${ }^{2}$ Novel Chemical Solutions, Crete, USA \\ Email: andrea.holmes@doane.edu
}

Received November 12, 2013; revised December 16, 2013; accepted December 25, 2013

Copyright (C) 2013 Macduff Okuom et al. This is an open access article distributed under the Creative Commons Attribution License, which permits unrestricted use, distribution, and reproduction in any medium, provided the original work is properly cited.

\begin{abstract}
The synthesis and characterization of a novel fluorophore(1), with potential application as an optical brightener are reported. This compound was prepared by reacting 4,4-diaminostilbene-2,2-disulfonic acid with cyanuric chloride in the presence of $\mathrm{Na}_{2} \mathrm{CO}_{3}$ followed by the addition of trityl aniline. Solution and solid state fluorescence demonstrated a strong blue/purple emission centered at $450 \mathrm{~nm}$. ${ }^{1} \mathrm{H}-\mathrm{NMR}$ spectroscopy, mass spectrometry analysis, elemental analysis, and DOSY-NMR were used for the characterization of the fluorophore.
\end{abstract}

Keywords: Optical Brightener; Fluorophore; Diaminostilbene; Cyanuric Chloride; Optical Brightness

\section{Introduction}

Optical brighteners are chromophores that typically absorb UV light (340 - $370 \mathrm{~nm})$ and emit blue light in the visible spectrum $(420-470 \mathrm{~nm})$. Optical brighteners are often derivatives of stilbene, biphenyl, naphthalene, anthracene and structurally related compounds [1]. Optical brighteners are used in cosmetics, detergents, and paints for changing the hue from yellow or grey to white $[2,3]$. This paper reports the synthesis of a new fluorophore that could have a potential application as an optical brightener.

The optical properties of these brighteners influence [2] the visual appearance and perception of skin imperfections, such as shadows, skin discolorations, wrinkles, and cellulite. Powders used to add pigment to colored cosmetics often employ optical brighteners exhibiting fluorescence in the solid state in addition to non-fluorescent additives. These additional components can be either organic or inorganic including iron oxides (yellow, red, brown, or black), ferric ammonium ferrocyanide (blue), manganese violet, ultramarine blue, chrome oxide (green), talc, lecithin modified talc, zeolite, kaolin, lecithin modified kaolin, titanium dioxide (white), and mixtures thereof $[4,5]$. Pearlants such as mica, bismuth, oxychloride and treated micas, such as titanated micas and lecithin modified micas, can also be used [4,5].

Desiring to create a new optical brightener with application in cosmetics, we synthesized compound 1 (Figure 1).

\section{Materials and Methods}

\subsection{Synthesis of 1}

1) A mixture of $25 \mathrm{~mL}$ of acetone and $20 \mathrm{~g}$ of ice were added to a 2-neck, $250 \mathrm{~mL}$ round bottom flask. $3.69 \mathrm{~g}$ of cyanuric chloride (2 equivalents) was added to the flask, and it was cooled to $0^{\circ} \mathrm{C}$ using an ice bath. The $\mathrm{pH}$ of the solution was increased to $4.5-5.5$ by the drop-wise addition of $10 \% \mathrm{Na}_{2} \mathrm{CO}_{3}$ solution (2 equivalents). $50 \mathrm{~mL}$ of water and $2.12 \mathrm{~g}$ of $\mathrm{Na}_{2} \mathrm{CO}_{3}$ were added slowly to $3.7 \mathrm{~g}$ of 4,4-diaminostilbene 2,2-disulfonic acid. The stilbene solution was then mixed with the cyanuric chloride solution while maintaining a temperature between $0^{\circ} \mathrm{C}$ and $5^{\circ} \mathrm{C}$. The solution was stirred for two hours at $0^{\circ} \mathrm{C}-5^{\circ} \mathrm{C}$. The resulting solution was filtered using a glass fritted filter and washed with ethyl acetate. The solid was dried under high vacuum overnight.

2) Diisopropylethylamine (DIPEA) (2.1 equivalents) was added to a $50 \mathrm{~mL}$ round bottom flask. THF, the intermediate from step 1, and 4-tritylaniline (2 equivalents) 


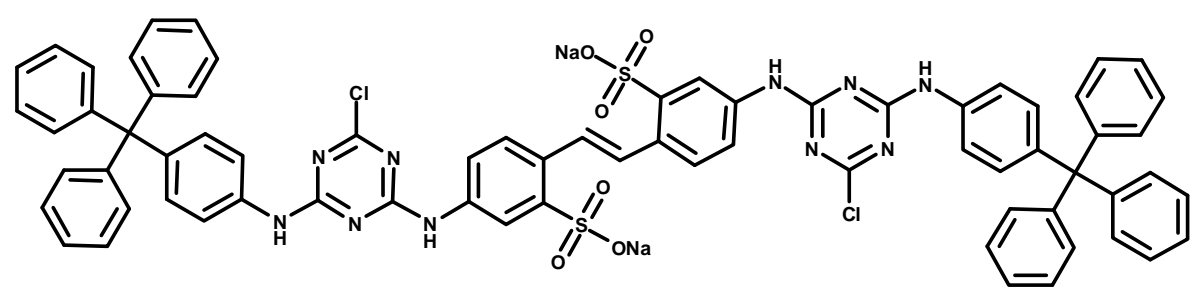

Figure 1. Chemical structure of bis-tritylaniline substituted compound with the IUPAC name bis-4,4-[6-Chloro-N-(4-tritylphenyl)-[1,3,5]triazine-2,4-diamine]-[2,2-disulfonic acid]-stilbene (1).

were added to the flask. The mixture was then refluxed overnight and filtered while still hot using a glass fritted filter. The product was washed with acetone and water, and then dried overnight.

\subsection{Characterization of 1}

For UV-Vis spectroscopy, $0.01 \mathrm{~g}$ of $\mathbf{1}$ was dissolved in 3 $\mathrm{mL}$ DMSO and diluted to $1.23 \times 10^{-5} \mathrm{~g} / \mathrm{mL}$. UV-Vis measurements were performed on a Varian Cary 50 Bio UV-Visible Spectrometer and absorbance data was collected from $200 \mathrm{~nm}-800 \mathrm{~nm}$ wavelengths. For fluorescence spectrometry, $0.01 \mathrm{~g}$ of $\mathbf{1}$ was dissolved in $3 \mathrm{~mL}$ of DMSO and diluted to a concentration of $1.23 \times 10^{-6}$ $\mathrm{g} / \mathrm{mL}$. Fluorescence measurements were performed on a Shimadzu RF-5301PC Fluorescence Spectrometer. The maximum absorption wavelength from the UV-Vis data was found to be $359 \mathrm{~nm}$ and was used as the excitation wavelength for the fluorescence spectroscopy experiments. Emission fluorescence data was collected from $400 \mathrm{~nm}-600 \mathrm{~nm}$. The excitation and emission slit widths were both set to $3 \mathrm{~mm}$. Solid state fluorescence of 1 was collected using a custom made fiber optic probe (Prizmatix Ltd., ModiinIlite, Israel). The excitation wavelength used in both solid state and solution fluorescence was $359 \mathrm{~nm}$ with excitation and emission slit width of 5 $\mathrm{mm}$ and data collected from $400-600 \mathrm{~nm}$. NMR data was collected using a Bruker Avance III $400 \mathrm{MHz}$ NMR Spectrometer. The NMR solvent used for the intermediate and the final product was deuterated DMSO. DOSY experiments were performed using a two-dimensional stimulated echo pulse sequence with bipolar gradient pulses for diffusion. MALDI mass spectra were obtained from the University of Nebraska-Lincoln using positive mode and $\alpha$-cyano-4-hydroxycinnamic matrix. Elemental analysis data was obtained from Micro-Analysis INC.

\section{Results and Discussion}

Our synthetic approach was based on previously reported schemes for polydentate ligands prepared in high yield by chloride substitution of 2,4,6-trichloro-1,3,5-triazine (cyanuric chloride) [6]. The synthesis of $\mathbf{1}$ (Scheme 1) proceeded at $0^{\circ} \mathrm{C}$ by the reaction of cyanuric chloride with diaminostilbene for two hours. After filtration and
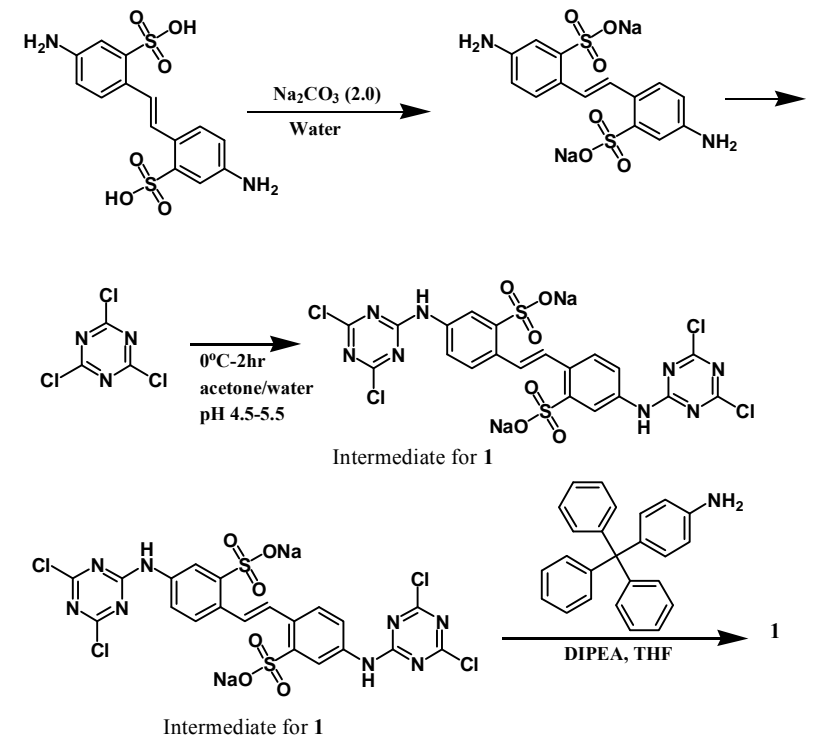

Scheme 1. Synthesis of 1 . First, diamino stilbene was treated with base ( 2 equivalents) to yield to diaminostilbene sodium salt. Next, cyanuric chloride was added to the solution at $0^{\circ} \mathrm{C}$ for two hours. The intermediate was isolated and washed with water. The intermediate was refluxed overnight with tritylaniline in the presence of DIPEA to give product 1 in $81 \%$ yield.

washing of the intermediate product, tritylaniline and DIPEA were added and refluxed overnight. The product was isolated in $81 \%$ yield.

Figure 2 shows the UV-Vis spectrum (Figure 2(a)), solution, and solid state fluorescence spectra of 1 (Figures 2(c) and (d)). Fluorescence spectroscopy and visual observation of blue fluorescence when the solid was exposed to a hand-held UV light demonstrated that the solid had strong fluorescent properties (Figure 2(b)). The $\lambda_{\max }$ of absorbance of 1 was $359 \mathrm{~nm}$. This wavelength allows 1 to fluoresce under sunlight conditions because the sun emits electromagnetic radiation across most of the electromagnetic spectrum (Figure 3). Furthermore, many incandescent light bulbs emit radiation starting at $300 \mathrm{~nm}$ (Figure 3), meaning that $\mathbf{1}$ can be excited to fluoresce by regular incandescent light bulbs and in sunlight. As seen in Figure 2(b), the fluorescence under UV-light conditions $(364 \mathrm{~nm})$ of 1increases dramatically as the concentration of 1 increases from $0.02 \%$ to $2 \%$. 


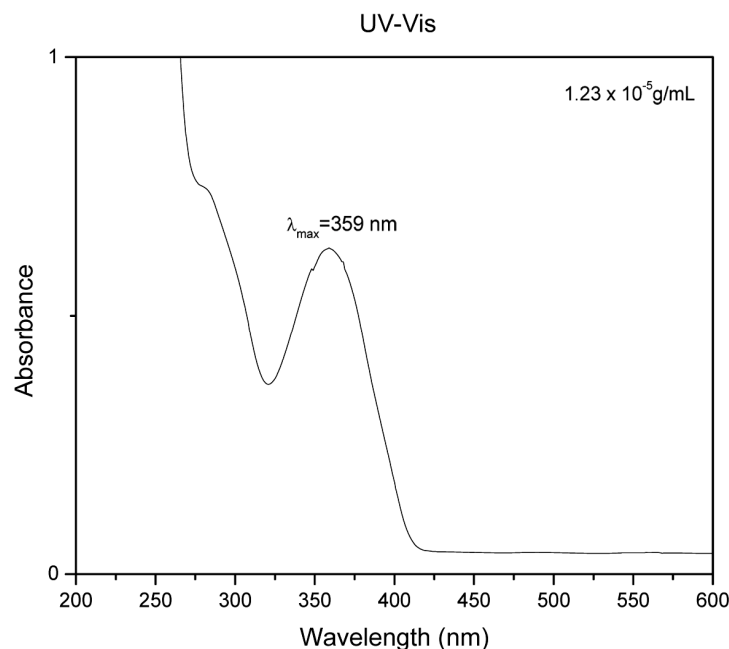

(a)

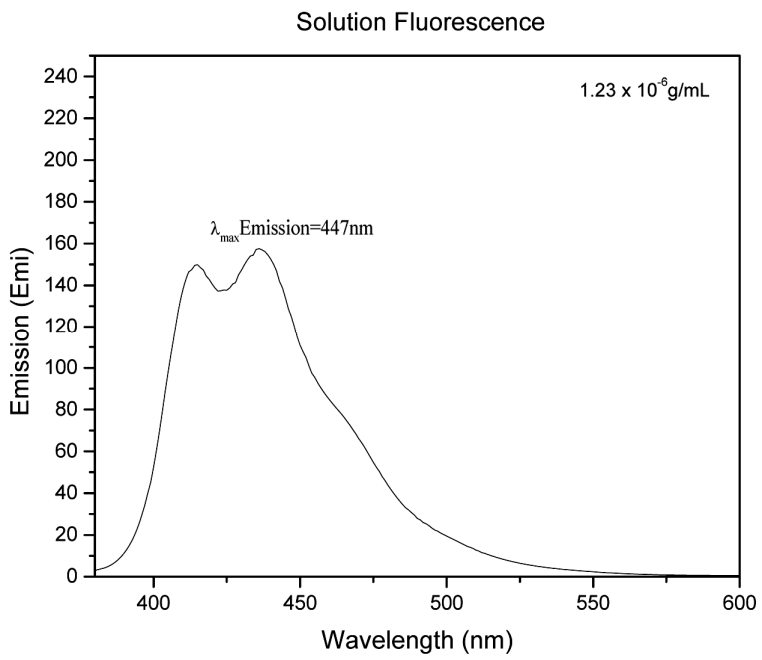

(c)

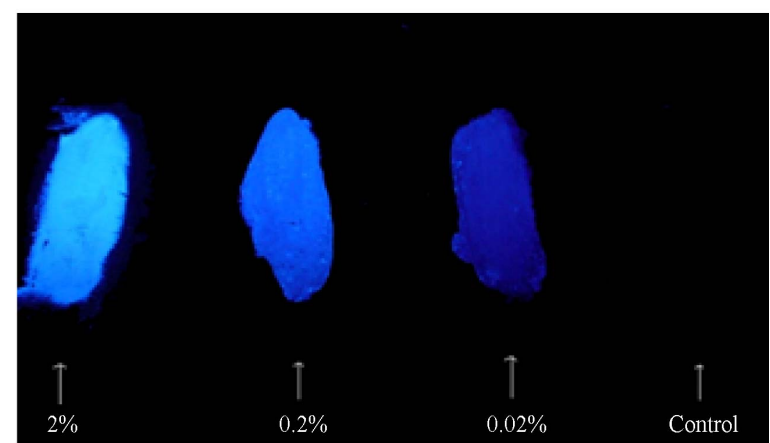

(b)

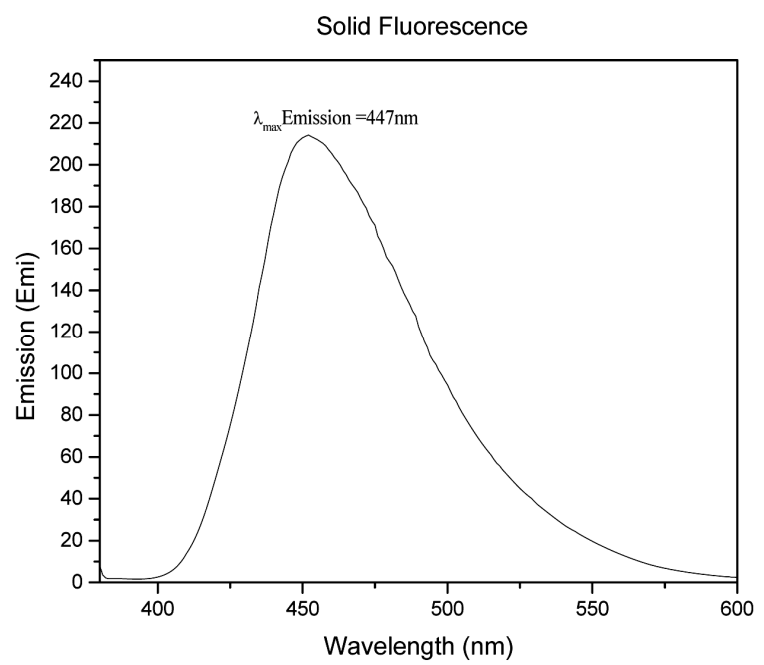

(d)

Figure 2. (a) UV-Vis of $11.23 \times 10^{-5} \mathrm{~g} / \mathrm{mL}$ in DMSO. The maximum absorbance is $359 \mathrm{~nm}$; (b) 1 formulated into liquid foundation at $2 \%, 0.2 \%$, and $0.02 \%$ and $0 \%$ (control) by weight under a hand-held $U V$ lamp. The fluorescent properties of 1 are visible even at very low concentrations like $0.02 \%$; (c) Solution fluorescence spectrum of 1 in DMSO at $1.23 \times 10^{-6} \mathrm{~g} / \mathrm{mL}$; (d) Solid fluorescence spectrum of 1.1 is highly fluorescent in the purple region as shown in the fluorescence spectra.

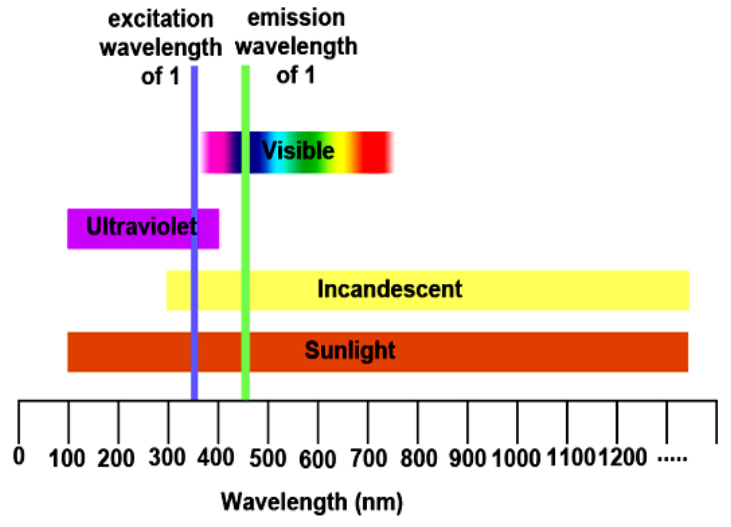

Figure 3. Chart of different light wavelengths compared to the excitation wavelength of 1 showing it can be excited under most types of lighting.
That means that if $\mathbf{1}$ would be used as a cosmetic additive, the formulation should only contain $0.02 \%$ or less in order to prevent a blue hue similar to what is seen when one wears a white T-shirt under black light conditions. The low percent loading of $(0.02 \%) 1$ in cosmetic products is actually very advantageous as this composition would allow for a large amount of product formulation. Even at a concentration as low as $1.23 \times 10^{-6} \mathrm{~g} / \mathrm{mL}, \mathbf{1}$ gives significant fluorescence emission, and is even more fluorescent in the solid state (Figure 2(d)). Fluorescence that is visible in both liquid and solid products make $\mathbf{1}$ very practical for cosmetic applications.

The relative formula mass of $\mathbf{1}$ was determined using mass spectrometry. Figure 4 shows the MALDI mass spectrum of $\mathbf{1}$. The peak with the highest intensity has 


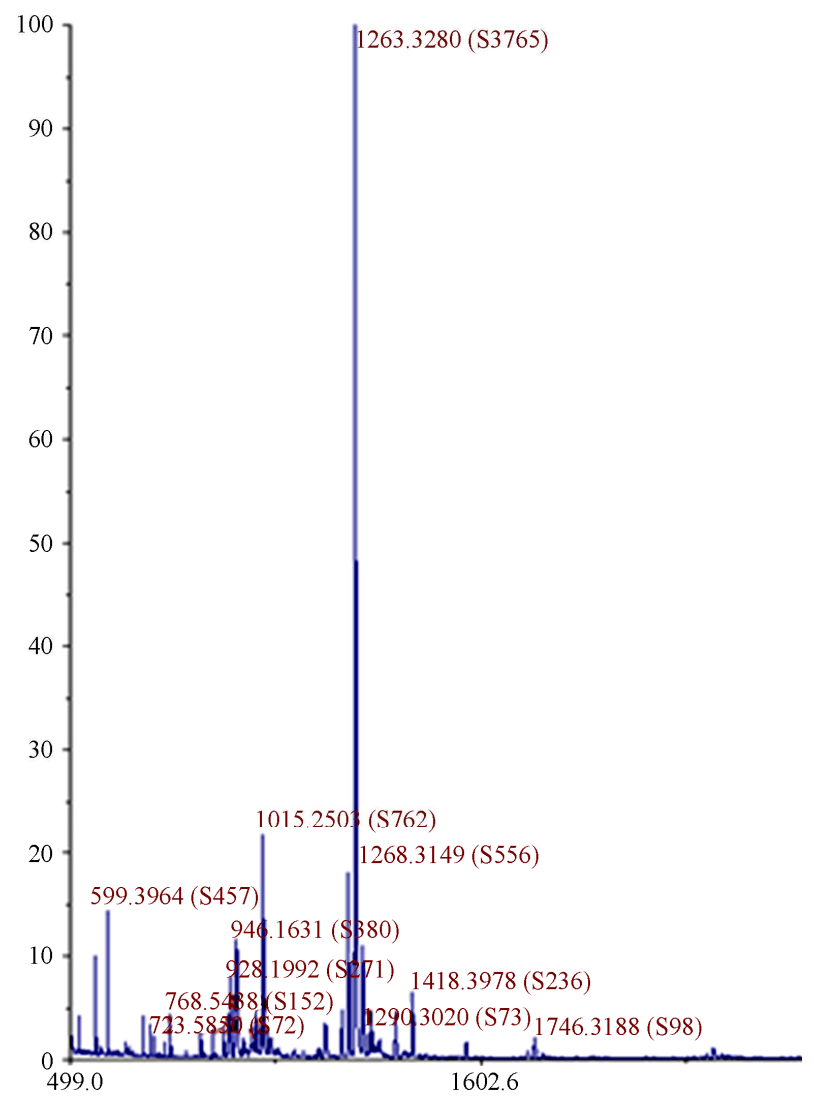

Figure 4. MALDI mass spectrum of 1 with a major peak at 1263 (the molar mass of 1) confirming 1 was synthesized in majority. Small impurities are also visible at lower and higher molecular masses.

mass to charge ratio of 1263 which corresponds to the molecular weight of $\mathbf{1}$. The mass spectrum shows the presence of small impurities of lower and higher molecular masses. These impurities were also confirmed in elemental analysis (Table 1) and ${ }^{1} \mathrm{H}-\mathrm{NMR}$ (Figure 5). The elemental analysis data of $\mathbf{1}$ is shown in Table $\mathbf{1}$. The expected elemental analysis was fitted by including water and DIPEA in the percent composition. DIPEA was used in the second step of the reaction (Scheme 1) and water was used for washing. It seems that 1 traps molecular impurities due to its "polar" properties. $\mathbf{1}$ is very hydrophilic due to its charged $\mathrm{SO}_{3}^{-}$groups, and water may adhere via intermolecular forces. $\mathbf{1}$ is also very hydrophobic due to its large and bulky tritylaniline groups. ${ }^{1} \mathrm{H}-\mathrm{NMR}$ of $\mathbf{1}$ is shown in Figure 5. The suggested proton assignments of $\mathbf{1}$ are demonstrated within the figure. It is evident from the spectrum that several peaks in the aromatic region $(7.5-8.5 \mathrm{ppm})$ are very broad. This indicates that $\mathbf{1}$ may form aggregates in solution that result in poor peak resolution. The doublet at 7.1 ppm may arise from the ethylene protons overlapping with two protons at the meta position of the first aromatic ring of the tritylaniline. Figure 6 shows the ${ }^{1}$ H-NMR of
Table 1. Elemental Analysis data of 1 obtained from MicroAnalysis, Inc. fitted with water and DIPEA.

\begin{tabular}{ccc}
\hline & $\begin{array}{c}\text { Elemental analysis } \\
\text { data of (1) }\end{array}$ & $\begin{array}{c}\text { (1) fitted with water } \\
\text { and DIPEA }\end{array}$ \\
\hline $\mathbf{C}$ & 62.94 & 63.64 \\
$\mathbf{H}$ & 6.52 & 6.55 \\
$\mathbf{N}$ & 10.18 & 10.12 \\
$\mathbf{O}$ & 8.93 & 11.56 \\
$\mathbf{S}$ & 3.87 & 3.86 \\
$\mathbf{C l}$ & 4.84 & 4.27 \\
\hline
\end{tabular}

the intermediate obtained from step 1 (Scheme 1). The resolution and multiplicity of the peaks are much better due to the fact that tritylaniline is not yet attached to cause aggregation in the solvent.

The spectrum shows several interesting features and the proton assignment was complicated due to the complexity of the final product in the presence of impurities. First, there are doublets at $7.6 \mathrm{ppm}, 7.8 \mathrm{ppm}$, and 8.07 $\mathrm{ppm}$. These doublets may arise from structural cis-trans isomerism. The starting material diaminostilbene was only $85 \%$ pure and consequently the intermediate contains two isomers in 85:15 ratio (trans versus cis). More overlapping peaks from 7.2 to $7.3 \mathrm{ppm}$ are assigned to the aromatic stilbene and aromatic ortho positions of tritylaniline. Six para protons of tritylaniline are located at $7.4 \mathrm{ppm}$. Two downfield peaks are present, one at 10.1 $\mathrm{ppm}$ and the other at $11.6 \mathrm{ppm}$. The peak at $11.6 \mathrm{ppm}$ indicates that the nitrogen on the tritylaniline must be protonated. Protons on ammonium ions can occur as far downfield as $11.6 \mathrm{ppm}$ [7]. The protonation of the nitrogen is due to the fact that when diaminostilbene is reacted with cyanuric chloride, $\mathrm{HCl}$ is formed as a side product and protonates the secondary nitrogen to form the $\mathrm{HCl}$ salt. The other downfield peak at $10.1 \mathrm{ppm}$ is due to either nitrogen protonation of unreacted starting material or intermediate, or $\mathrm{SO}_{3}^{-}$groups on the aromatic rings becoming protonated at low $\mathrm{pH}$. In addition to conventional characterization techniques such as ${ }^{1} \mathrm{H}$ NMR, to determine purity, we also examined the products by diffusion ordered spectroscopy (DOSY) [8] as shown in Figure 7.

$\mathrm{A}^{1} \mathrm{H}$-NMR spectrum is obtained in the horizontal axis, while the diffusion coefficient (D) is obtained in the vertical axis. Since the diffusion constant depends on molecular size, the vertical axis provides an estimate for the number of components that are present in a mixture $[8,9]$. The measurement of diffusion is carried out by observing the attenuation of the NMR signals during a pulsed field gradient experiment. 


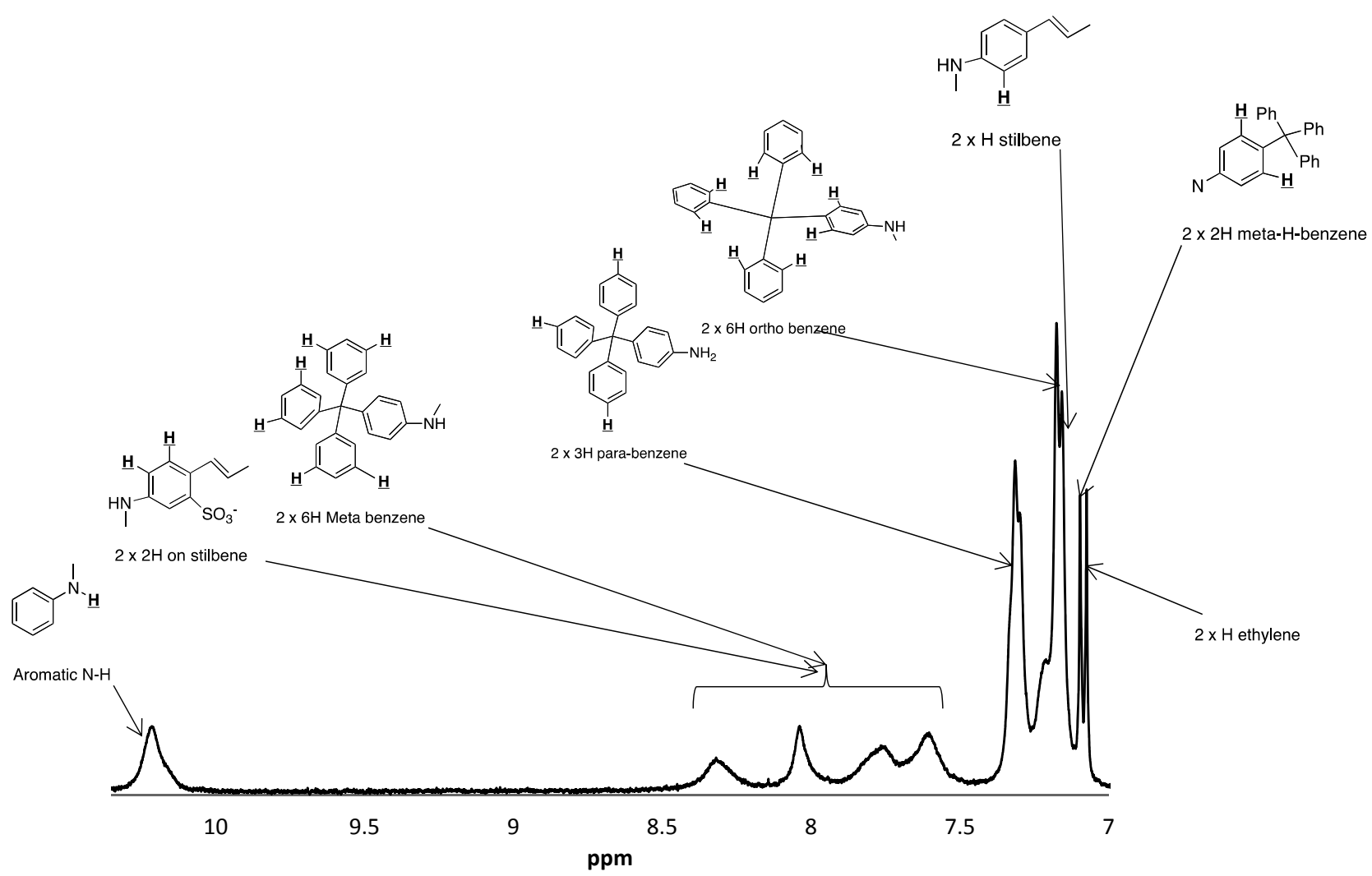

Figure 5. The aromatic region of the ${ }^{1} \mathrm{H}$-NMR spectrum of 1 in DMSO showing the proton peak assignment. The broad peaks from 7.5 to $8.5 \mathrm{ppm}$ indicate that 1 forms aggregates in DMSO.

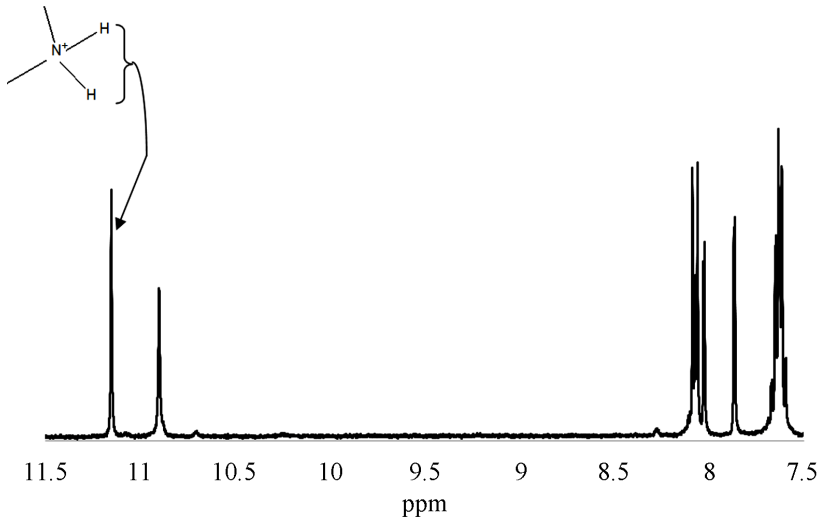

(a)

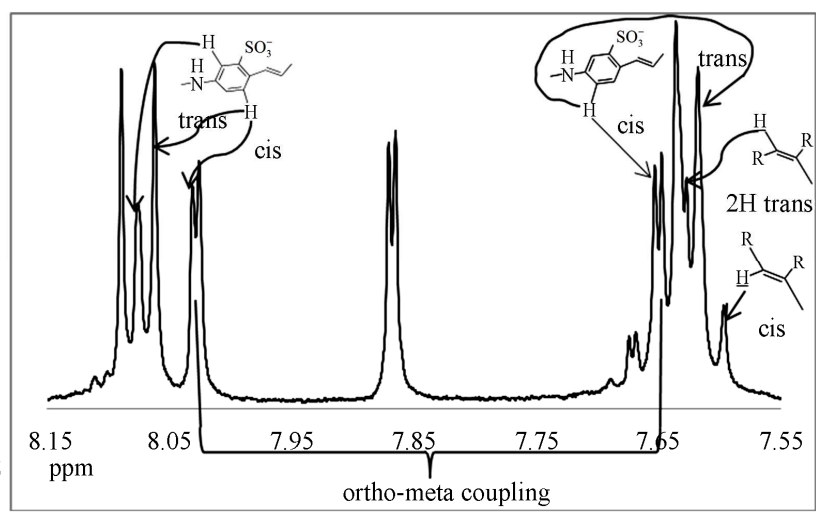

(b)

Figure 6. (a) ${ }^{1} \mathrm{H}-\mathrm{NMR}$ spectrum of wild-plum intermediate, showing the amine proton peak assignment; (b) ${ }^{1} \mathrm{H}-\mathrm{NMR}$ spectrum of wild-plum intermediate showing the peak assignment for the aromatic region.

Figure 7 shows that the aromatic region demonstrated the highest signal intensity which is attributed to the protons in the aromatic 1. Residual solvent (THF and DIPEA) peaks are also visible in small quantities at $3.1,3.5$, and $3.6 \mathrm{ppm}$.

\section{Conclusion}

1 was synthesized with reasonably high purity and yield ( 81\%). Characterization of 1 by ${ }^{1} \mathrm{H}-\mathrm{NMR}$, mass spec- trometry, elemental analysis, and DOSY-NMR confirmed the structure of $\mathbf{1}$ (as shown in Figure 1). $\mathbf{1}$ is highly fluorescent in the purple region in both the solid and dissolved state. It is able to fluoresce under normal lighting conditions, which makes it a viable candidate as an optical brightener in cosmetics, paper, paints, or detergents.

\section{Acknowledgements}

The authors are grateful to the National Science Founda 


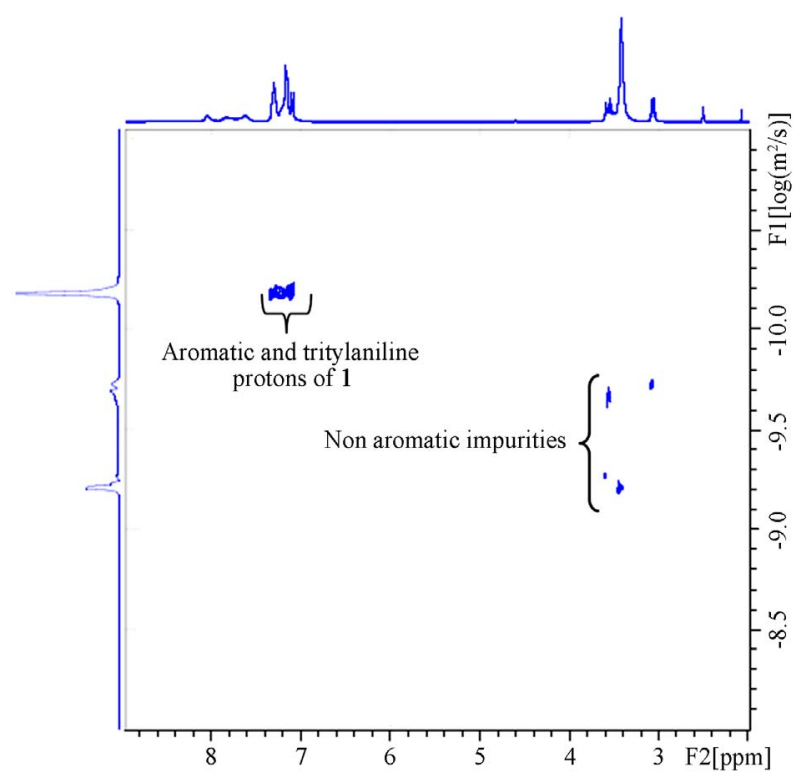

Figure 7. DOSY NMR spectrum of 1. The highest signal intensity was found for 1 in the aromatic region between 7 8 ppm. Aliphatic impurities, solvents, and residual DIPEA are seen in small quantities in the aliphatic region.

tion (NSF) for providing funds for this project through Nebraska Center for Nanohybrid Functional Materials (CNFM) grant NSF-EPSCoR-EPS-1004094 and NSFCHE1040402 and The National Institutes of Health (NIH) for grant Nos. P20 RR016474 (M.B.) and P20 RR016469 (A.E.H.).

\section{REFERENCES}

[1] S. Dufresne, M. Gaultois and W. G. Skene, "Disodium 5,5'-Diamino-2,2'-ethylenedibenzenesulfonate Tetrahydrate," Acta Crystallographica, Vol. 63, 2007, p. E63.

[2] M. A. Hubbe, J. J. Pawlak and A. A. Koukoulas, "Paper's Appearance: A Review," BioResources, Vol. 3, No. 2, 2008, pp. 627-665.

[3] I. D. Cohen, "Cosmetic Compositions Containing Optical Brighteners," US Patent No: 09/320153, 1999.

[4] US Food and Drug Administration, "Color Additives Inventory."

http://www.fda.gov/forindustry/coloradditives/coloradditi veinventories/ucm115641.htm

[5] "Cosmetics Info."

http://www.cosmeticsinfo.org/products.php?category_id=7

[6] P. de Hoog, P. Gamez, W. L. Driessen and J. Reedijk, "New Polydentate and Polynucleating N-Donor Ligands from Amines and 2,4,6-Trichloro-1,3,5-triazine," Tetrahedron Letters, Vol. 43, No. 38, 2002, pp. 6783-6786. http://dx.doi.org/10.1016/S0040-4039(02)01498-3

[7] "Proton Chemical Shifts." http://www.chemwisc.edu/areas/reich/handouts/nmr-h/hd ata $\{31\}$.gif

[8] G. Morris, "Diffusion-Ordered Spectroscopy," John Wiley \& Sons Ltd., Chinchester, 2009.

[9] D. Fujita, K. Suzuki, S. Sato and M. E. A. Yagi-Utsumi, "Protein Encapsulation within Synthetic Molecular Hosts," Nature Commications, Vol. 3, 2012, p. 1093. http://dx.doi.org/10.1038/ncomms2093 